\title{
POTENSI ENERGI PANAS BUMI DAN REKOMENDASI PEMANFAATANNYA PADA DAERAH HARUKU MALUKU TENGAH
}

\section{Potential of Geothermal Energy and Recommended Utilization in The Haruku Area, Central of Maluku}

\author{
Helda Andayany $^{1 *}$, Mirtha Yunitha Sari Risakota ${ }^{2}$ \\ ${ }^{1,2}$ Jurusan Fisika, Fakultas MIPA, Universitas Pattimura \\ Jln. Ir. M. Putuhena, Kampus Unpatti, Poka-Ambon, 97233, Indonesia \\ e-mail: 1* heldaandayany2014@gmail.com ; 2 mithayunisari@gmail.com \\ Corresponding Author*
}

\begin{abstract}
Abstrak
Penelitian ini adalah menganalisis karakteristik mineral ubahan dengan metode FTIR di daerah mata air panas Haruku, Maluku Tengah. Hasil analisis FTIR menunjukkan jenis mineral ubahan yang mendominasi daerah panas bumi Haruku adalah mineral aragonit dan kalsit yang terdapat pada jenis batuan karbonat. Kedua mineral ini merupakan hasil alterasi dari batuan induk karena suhu reservoir dan suhu di permukaan yang tinggi. Mineral aragonit dan kalsit diinterpretasi terbentuk secara bersamasama pada suhu permukaan $55^{\circ} \mathrm{C}$. Di bawah suhu $55^{\circ} \mathrm{C}$ hanya kalsit yang dapat terbentuk. Mineral aragonit mengalami rekristalisasi dengan porositas yang tinggi. Sebaliknya, mineral kalsit mengalami rekristalisasi dengan porositas yang rendah. Hasil pengukuran suhu air panas rata-rata di permukaan adalah $58,8^{\circ} \mathrm{C}$. Karakteristik air panas pada daerah Haruku Maluku Tengah juga didukung dengan $\mathrm{pH}$ adalah 7,1 dan konduktivitas listrik berkisar $(9,350-10,450) \mu \mathrm{S} / \mathrm{m}$. Pengukuran debit alir berkisar $(0,11-$ $0,16) \mathrm{m}^{3} /$ detik memberikan hasil perhitungan kehilangan panas (heat loss) adalah $80 \mathrm{~kW}$. Pendugaan suhu reservoir panas bumi pada daerah Haruku Maluku Tengah berkisar $240^{\circ} \mathrm{C}$, sehingga dapat berpotensi sebagai lapangan panas bumi untuk digunakan sebagai dasar rekomendasi utilisasi potensi panas bumi bagi pemerintah daerah (indirect use) yaitu sebagai informasi untuk memenuhi kekurangan daya listrik di daerah Maluku Tengah dan Maluku secara umum.
\end{abstract}

Kata Kunci : Utilisasi potensi panas bumi, daya listrik, suhu reservoir.

\begin{abstract}
This research is to analyze the characteristics of minerals by FTIR method in Haruku Central Of Maluku hot springs area. The FTIR analysis results indicate the type of mineral that dominates the geothermal area of Haruku is the aragonite and calsite minerals found in the type of carbonate rock which is the result of alteration from the parent rock due to the reservoir temperature and high surface temperature. Aragonite and calcite minerals are interpreted of formed together at a surface temperature of $55^{\circ} \mathrm{C}$. Below $55^{\circ} \mathrm{C}$, only calcite can be formed. The mineral aragonite undergo recrystallization with high porosity. In contrast, calcite minerals undergo recrystallization with low porosity. The result of measurement of mean hot water temperature at very high surface is $58,8^{\circ} \mathrm{C}$. The characteristics of hot water in the Haruku area of Central Maluku are also supported with $\mathrm{pH}$ is 7.1 and the electrical conductivity ranges $(9,350-10,450) \mu \mathrm{S} / \mathrm{m}$. The measurement of flowing flowrate $(0,11-0,16) \mathrm{m}^{3} / \mathrm{seconds}$ giving the result of heat loss calculation is $80 \mathrm{~kW}$. The estimation of geothermal reservoir temperature in Haruku Central Maluku area is $240^{\circ} \mathrm{C}$, so it is potential as geothermal field to be used as the base of geothermal potential utilization recommendation for local government (indirect use) namely as information to meet the lack of electricity in the area of Central Maluku and Maluku in general.
\end{abstract}

Keywords: Utilization of geothermal potential, electrical power, reservoir temperature. 


\section{PENDAHULUAN}

Panas bumi merupakan sumber daya alam yang mempunyai peranan penting sebagai salah satu sumber energi alternatif yang renewable. Sumber daya alam ini dapat diperbarui dan pemanfaatannya relatif ramah lingkungan dan dapat mengurangi ketergantungan terhadap bahan bakar minyak bumi. Pada dasarnya sistem panas bumi merupakan suatu daur hidrologi air (air tanah dan hujan) yang dalam perjalanannya berhubungan dengan sumber panas (heat source) bertemperatur tinggi, sehingga terbentuk air panas yang dapat terperangkap dalam batuan yang mempunyai permeabilitas tinggi. Fluida dan batuan reservoir dalam sistem panas bumi biasanya saling berinteraksi mengakibatkan perubahan fase padat dan cair, sehingga menghasilkan mineral baru atau mineral ubahan. Perubahan fase ini disebabkan adanya distribusi suhu yang berbeda-beda dalam reservoir panas bumi. Secara umum bentuk alterasi hidrotermal meliputi mineralogi, tekstur, dan respons kimia batuan termal maupun lingkungan kimianya berubah ditandai oleh kenampakan air panas, uap air, dan gas. Uap air dan air panas tersebut akan muncul ke permukaan melalui struktur-struktur seperti sesar, atau rekahan [6].

Air yang bersifat asam $(\mathrm{pH}<7)$ terdapat pada daerah-daerah dengan endapan vulkanik, sedangkan air yang bersifat basa $(\mathrm{pH}>7)$ terdapat pada daerah-daerah dengan batuan ultramafik. Reaksi antara air dengan batuan ultramafik membentuk serpentinit. Air panas memiliki $\mathrm{pH}$ rendah karena konsentrasi ion $\mathrm{H}^{+}$ di dalam sistem lebih besar. $\mathrm{pH}$ air rendah biasanya menunjukkan fluida panas berasal dari sistem panas bumi dominasi uap dan $\mathrm{pH}$ air netral biasanya menunjukkan fluida panas berasal dari sistem panas bumi dominasi air, yang biasanya mengandung silika. Apabila laju aliran air panas tidak terlalu besar, maka umumnya di sekitar air panas tersebut terbentuk teras-teras silika yang berwarna kepekahan (silica sinter terraces atau sinter platforms) [1].

Marini dan Susangkyono (1999) [7] menyebutkan bahwa saat ini Indonesia mempunyai total potensi sumber daya dan cadangan panas bumi sebesar 27.189 MW (yaitu potensi sebesar 14.244 MW, cadangan terduga $9.912 \mathrm{MW}$, mungkin $728 \mathrm{MW}$, dan terbukti $2.305 \mathrm{MW}$ ) atau sekitar $40 \%$ potensi dunia. Meskipun demikian baru 807 MW dari total potensi tersebut yang dimanfaatkan untuk memenuhi kebutuhan listrik Indonesia. Kabupaten Maluku Tengah terdapat 8 lokasi yang meliputi Larike, Tulehu, Haruku, Saparua, Nusalaut, Tehoru, Banda Baru dan Pohon Batu diduga memiliki potensi sumber energi panas bumi 400 MW.

Tjokrosapoetro et al. (2003) [10] menyebutkan bahwa salah satu daerah potensi panas bumi di daerah Maluku Tengah adalah Haruku. Struktur sesar normal Haruku yang berarah Barat Daya sampai Timur Laut. Sesar ini berperan besar memunculkan manifestasi air panas di daerah Haruku Maluku Tengah dengan suhu di permukaan adalah $55^{\circ} \mathrm{C}$. Keadaan fisik di lokasi sekitar mata air panas Haruku menunjukkan terdapat material berwarna coklat kemerahan di permukaannya dan batuan sekitar teralterasi atau sudah mengalami ubahan dari batuan induk.

Potensi panas bumi yang terjadi pada batuan karena adanya proses alterasi hidrotermal yang membentuk mineral ubahan yang dapat mengubah densitas batuan tergantung pada jenis mineral yang dibentuk pada suatu reservoir panas bumi [11]. Selain Haruku, Tehoru merupakan salah satu daerah prospek panas bumi di Maluku Tengah. Temperatur reservoir di daerah ini diperkirakan sebesar $210^{\circ} \mathrm{C}$ yang termasuk ke dalam temperatur sedang. Hasil kompilasi data terpadu memperlihatkan zona prospek panas bumi daerah Tehoru diperkirakan berada di sekitar manifestasi mata air panas Tehoru dengan luas kurang lebih $6 \mathrm{~km}^{2}$. Potensi sumber daya hipotetik daerah panas bumi Tehoru adalah sekitar $40 \mathrm{MWe}$ [5].

Penyelidikan suhu reservoir panas bumi di daerah Haruku dan Tehoru Kabupaten Maluku Tengah dengan menggunakan persamaan geotermometer empiris $\left(\mathrm{SiO}_{2}\right) \mathrm{p}$ memberikan suhu reservoir pada daerah panas bumi Haruku antara $(185 \pm 1.0)^{\circ} \mathrm{C}$ to $(190 \pm 1.1)^{\circ} \mathrm{C}$ dan Tehoru antara suhu $(185 \pm 1.0)^{\circ} \mathrm{C}$ to $(190 \pm$ $1.1)^{\circ} \mathrm{C}$. Kenampakan suhu air panas di permukaan pada mata air panas Haruku berkisar antara $(58-59)^{\circ} \mathrm{C}$ dan Tehoru berkisar antara $(60-61)^{\circ} \mathrm{C}$. Hal ini menunjukkan bahwa daerah Haruku dan Tehoru berpotensi sebagai lapangan panas bumi di daerah Maluku Tengah [3].

Salah satu penyebab belum maksimum pemanfaatan potensi panas bumi yang tersebar di Kabupaten Maluku Tengah adalah karena ketidakpahaman tentang karakteristik mineral ubahan yang terdapat disekitar mata air panas. Sehingga telah dilakukan penelitian untuk menganalisis karakteristik mineral ubahan menggunakan metode FTIR (Fourier Transform Infra Red). Metode FTIR (Fourier Transform Infra Red) ini dapat digunakan untuk mengidentifikasi suatu senyawa yang belum diketahui, 
karena spektrum yang dihasilkan oleh suatu senyawa adalah khas dan oleh karena itu dapat menyajikan sebuah finger print (sidik jari) untuk senyawa tersebut [8].

Penelitian ini bertujuan untuk mengetahui karakteristik mineral ubahan di sekitar mata air panas dan suhu reservoir sumber panas bumi di daerah Haruku Maluku Tengah. Penelitian mendalam adalah dengan memperkirakan kehilangan panas (heat loss) yang dihitung berdasarkan pengukuran debit alir air panas di sekitar mata air panas Haruku Maluku Tengah [2].

\section{METODE PENELITIAN}

Secara geografis pulau Haruku terletak antara $3^{\circ} 30^{\prime} 38.88^{\prime \prime}-3^{\circ} 38^{\prime} 14.64^{\prime \prime}$ LS and 128 $23^{\prime} 54.24^{\prime \prime}$ $128^{\circ} 34^{\prime} 40.8^{\prime \prime}$ BT. Peta pulau Haruku disajikan pada Gambar 1 [4].

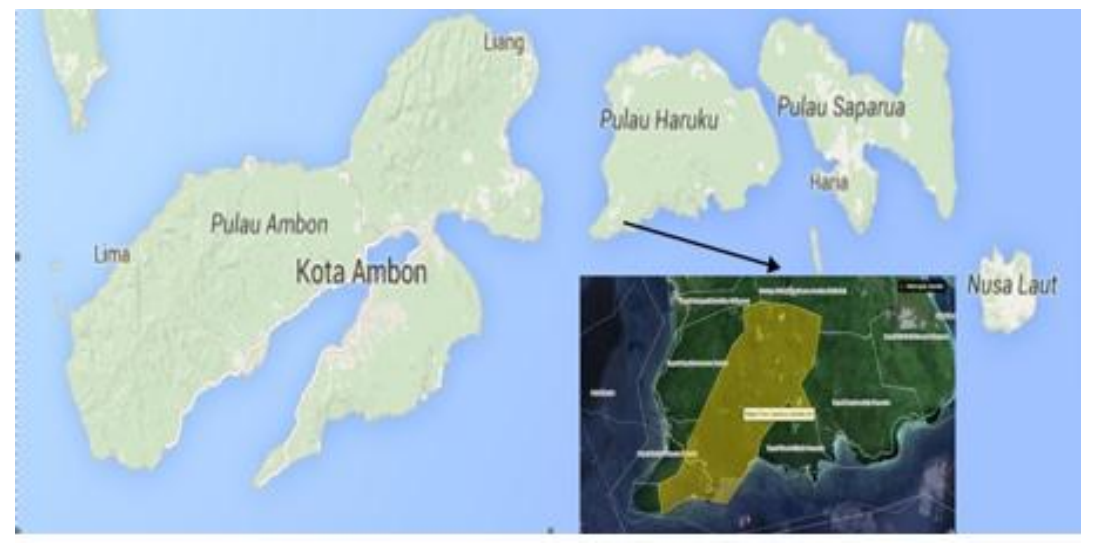

Gambar 1. Peta Pulau Haruku

Pada beberapa manifestasi air panas di daerah Haruku, Maluku Tengah terdapat mineral ubahan yang terbentuk di permukaan sekitar mata air panas. Kenampakan mineral ubahan ini dapat menunjukkan karakteristik air panas yang pernah berinteraksi dengan batuan sekitar. Untuk mengetahui karakteristik mineral ubahan maka telah dilakukan pengukuran suhu, $\mathrm{pH}$ dan konduktivitas air panas di permukaan selama monitoring 1 x 24 jam dengan interval waktu pengukuran tiap 30 menit. Hal ini dilakukan untuk memperoleh data pengukuran rata-rata suhu, $\mathrm{pH}$, dan konduktivitas air panas di permukaan untuk mengetahui karakteristik mineral ubahan dan suhu di reservoir. Suhu dipermukaan diukur dengan Xplorer GLX yang dilengkapi sensor suhu lingkungan dan sensor suhu air (Stainless Sted Probe) PS-215, sensor pH dan sensor konduktivitas. Selain itu juga dilakukan pengambilan sampel batuan di sekitar mata air panas. Selanjutnya mineralogi penyusun batuan ubahan dideskripsi dengan menggunakan analisis FTIR (Fourier Transform Infra Red). Analisis sampel batuan dengan FTIR untuk mengetahui jenis mineral ubahan dan karakteristik mineral ubahan.

Selain itu, penelitian ini memperkirakan besar potensi panas bumi melalui perhitungan kehilangan panas (heat loss) yang dihitung berdasarkan pengukuran debit alir air panas di sekitar mata air. Hilang panas alamiah ini dihitung berdasarkan rumus yang diberikan oleh Hochstein (1990) dalam Saptadji (2009) [9], yaitu:

$$
Q=m\left(h . f . T-h . f . T_{0}\right) \approx m \cdot c \cdot\left(T-T_{0}\right)
$$

dengan:

$Q$ adalah hilang panas $(\mathrm{kW})$;

$m$ adalah debit aliran yang keluar $\left(\mathrm{m}^{3} /\right.$ detik);

h. f.T-h.f.T $T_{0}$ adalah entalpi fluida $(\mathrm{kJ} / \mathrm{kg})$;

$c$ adalah kapasitas panas spesifik $\left(\mathrm{kJ} / \mathrm{kg} .{ }^{\circ} \mathrm{C}\right),\left(c\right.$ untuk air memiliki nilai rata-rata $4,2 \mathrm{~kJ} / \mathrm{kg} .{ }^{\circ} \mathrm{C}$ );

$T$ adalah temperatur mata air panas dan

$T_{0}$ adalah temperatur udara rata-rata tahunan. 
Perhitungan kehilangan panas secara alamiah dihitung sesuai dengan tipe manifestasi panas buminya. Untuk kolam air panas atau hangat, perhitungan kehilangan panas harus memperhitungkan proses evaporasi. Untuk kolam-kolam yang mempunyai dimensi kurang dari $1000 \mathrm{~m}^{2}$, umumnya digunakan pendekatan empiris dengan nilai hilang panas alamiah yang sesuai dengan temperatur kolam.

Pendugaan besar potensi panas bumi di daerah Haruku dapat digunakan sebagai dasar rekomendasi utilisasi potensi panas bumi bagi pemerintah daerah (indirect use) yaitu sebagai informasi untuk memenuhi kekurangan daya listrik di daerah Maluku Tengah dan Maluku secara umum.

\section{HASIL DAN PEMBAHASAN}

Lokasi penelitian di daerah panas bumi Haruku, Maluku Tengah secara geografis terletak antara 3,34 Lintang Selatan dan 128,29 Bujur Timur. Hasil pengukuran suhu, pH dan konduktivitas air panas di permukaan selama monitoring 1 x 24 jam dengan interval waktu pengukuran tiap 30 menit diberikan pada Tabel 1. Suhu rata-rata di permukaan mata air panas Haruku adalah $58,5^{\circ} \mathrm{C}$. Hal ini menunjukkan bahwa suhu permukaan air panas cukup tinggi.

Tabel 1. Hubungan antara suhu, $\mathrm{pH}$, konduktivitas listrik dan debit alir yang terukur di permukaan air panas dengan interpretasi suhu reservoir daerah panas bumi Haruku.

\begin{tabular}{|l|l|}
\hline \multicolumn{1}{|c|}{ Besaran } & \multicolumn{1}{c|}{ Nilai } \\
\hline Suhu $\left({ }^{\circ} \mathrm{C}\right)$ & 58,8 \\
\hline $\mathrm{pH}( \pm 0,01)$ & 7,1 \\
\hline Konduktivitas $(\mu \mathrm{S} / \mathrm{m})$ & $(9,350-10,450)$ \\
\hline Debit Alir $\left(\mathrm{m}^{3} /\right.$ detik $)$ & $(0,11-0,16)$ \\
\hline Suhu Reservoir $\left({ }^{\circ} \mathrm{C}\right)$ & 240 \\
\hline Hilang panas $(\mathrm{kW})$ & 80 \\
\hline
\end{tabular}

Berdasarkan Tabel 1, hasil pengukuran suhu air panas rata-rata di permukaan yaitu $58,8^{\circ} \mathrm{C}$. Karakteristik air panas di daerah Haruku juga didukung dengan $\mathrm{pH}$ adalah 7.1 dan konduktivitas listrik berkisar $(9,350$ $10,450)(\mu \mathrm{S} / \mathrm{m})$. Pengukuran debit alir berkisar $(0,11-0,16) \mathrm{m}^{3} /$ detik memberikan hasil perhitungan kehilangan panas (heat loss) adalah $80 \mathrm{~kW}$ yang diberikan pada tabel 2. Dengan pengukuran langsung suhu di permukaan yang tinggi, $\mathrm{pH}$, konduktivitas dan debit alir di permukaan mata air panas, maka dapat diinterpretasi suhu reservoir panas bumi Haruku berkisar $240^{\circ} \mathrm{C}$. Data ini juga didukung dari hasil pemodelan sumber panas bumi dengan metode 2D di daerah Oma-Haruku [10]. Dengan demikian, suhu reservoir di daerah Haruku dapat diklasifikasikan dalam sistem panas bumi suhu tinggi [9]. Hal ini menunjukkan bahwa daerah Haruku dapat berpotensi sebagai lapangan panas bumi untuk digunakan sebagai dasar rekomendasi utilisasi potensi panas bumi bagi pemerintah daerah (indirect use) yaitu sebagai informasi untuk memenuhi kekurangan daya listrik di daerah Maluku Tengah dan Maluku secara umum.

Tabel 2. Hasil perhitungan kehilangan panas (heat loss) alamiah daerah panas bumi Haruku.

\begin{tabular}{|c|c|c|c|c|c|c|c|}
\hline $\begin{array}{c}\text { Kode } \\
\text { Station } \\
\text { Pengukuran }\end{array}$ & $\begin{array}{c}\text { Debit Alir } \\
\left(\mathrm{m}^{3} / \mathrm{detik}\right)\end{array}$ & $\begin{array}{c}\mathrm{T} \\
\left({ }^{\circ} \mathrm{C}\right)\end{array}$ & $\begin{array}{c}\mathrm{T}_{\mathrm{o}} \\
\left({ }^{\circ} \mathrm{C}\right)\end{array}$ & $\begin{array}{c}\text { h.f.T } \\
(\mathrm{kJ} / \mathrm{kg})\end{array}$ & $\begin{array}{c}\text { h.f. } T_{0} \\
(\mathrm{~kJ} / \mathrm{kg})\end{array}$ & $\begin{array}{c}\Delta h f \\
(\mathrm{~kJ} / \mathrm{kg})\end{array}$ & $\begin{array}{c}\mathrm{Q} \\
(\mathrm{kW})\end{array}$ \\
\hline $\mathrm{s}-1$ & 0,11 & 58 & 29 & 240 & 118 & 122 & 13,4 \\
\hline $\mathrm{s}-2$ & 0,16 & 59 & 26 & 245 & 106 & 139 & 22,2 \\
\hline $\mathrm{s}-3$ & 0,16 & 58,5 & 25,5 & 242 & 103 & 139 & 22,2 \\
\hline $\mathrm{s}-4$ & 0,16 & 59,5 & 26,5 & 246 & 107 & 139 & 22,2 \\
\hline \multicolumn{7}{|c}{ Q total (kW) } \\
\hline
\end{tabular}

Berdasarkan Gambar 2, grafik specktrum absorbansi menunjukan bahwa adanya gugus $\mathrm{OH}$ yang menandakan terdapat serapan alkohol/fenol pada nilai bilangan gelombang antara $3600-3820 \mathrm{~cm}^{-1}$. Selain itu, puncak serapan yang paling tinggi dari sampel tersebut adalah berada pada nilai dengan bilangan gelombang $1870 \mathrm{~cm}^{-1}$ dengan gugus fungsinya adalah $\mathrm{C}=\mathrm{O}$. Untuk daerah serapan dengan panjang gelombang pada kisaran ini jenis mineralnya adalah kalsit. Selain itu terdapat juga nilai bilangan 
gelombang yang berkisar antara $1690 \mathrm{~cm}^{-1}$ yang dibentuk oleh gugus fungsi $\mathrm{C}=\mathrm{O}$ mengidentifikasikan jenis mineral Aragonit.

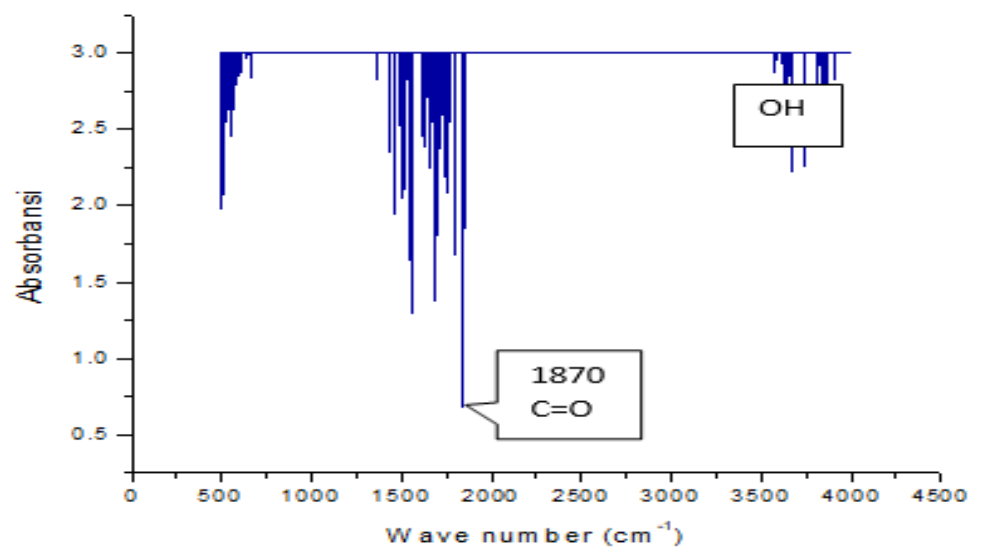

Gambar 2. Grafik Spektrum Absorbansi

Hasil analisis FTIR menunjukkan jenis mineral ubahan yang mendominasi daerah panas bumi Haruku adalah mineral aragonit dan kalsit yang terdapat dalam batuan karbonat. Kedua mineral ini merupakan hasil alterasi dari batuan induk yang disebabkan suhu reservoir sedang yaitu berkisar $240^{\circ} \mathrm{C}$ dan suhu di permukaan yang tinggi yaitu $58,8^{\circ} \mathrm{C}$. Mineral aragonit dan kalsit diinterpretasi terbentuk secara bersama-sama pada suhu permukaan $55^{\circ} \mathrm{C}$. Di bawah suhu $55^{\circ} \mathrm{C}$ hanya kalsit yang dapat terbentuk. Mineral aragonit mengalami rekristalisasi dengan porositas yang tinggi. Sebaliknya, mineral kalsit mengalami rekristalisasi dengan porositas yang rendah.

\section{KESIMPULAN}

Berdasarkan interpretasi suhu tinggi yang berkisar $240^{\circ} \mathrm{C}$ pada reservoir panas bumi Haruku dan suhu di permukaan yang tinggi yaitu $58,8^{\circ} \mathrm{C}$ menyebabkan batuan di sekitar mata air panas sudah teralterasi atau sudah mengalami ubahan dari batuan induk. Selain itu, hasil analisis sampel batuan dengan FTIR menunjukkan jenis mineral ubahan yang mendominasi daerah panas bumi Haruku adalah mineral aragonit dan kalsit yang terdapat dalam batuan karbonat. Kedua mineral ini merupakan hasil alterasi dari batuan induk. Mineral aragonit mengalami rekristalisasi dengan porositas yang tinggi. Sebaliknya, mineral kalsit mengalami rekristalisasi dengan porositas yang rendah. Proses rekristalisasi kedua mineral ubahan ini sangat dipengaruhi oleh suhu reservoir dan suhu dipermukaan yang tinggi. Dengan adanya kenampakan mineral ubahan, suhu reservoir sedang dan perhitungan kehilangan panas (heat loss) sebesar $80 \mathrm{~kW}$ menunjukkan bahwa Haruku dapat berpotensi sebagai lapangan panas bumi untuk digunakan sebagai dasar rekomendasi utilisasi potensi panas bumi bagi pemerintah daerah (indirect use) yaitu sebagai informasi untuk memenuhi kekurangan daya listrik di daerah Maluku Tengah dan Maluku secara umum.

\section{UCAPAN TERIMA KASIH}

Terima kasih banyak ditujukan kepada Dekan Fakultas Matematika dan Ilmu Pengetahuan Alam Universitas Pattimura melalui Laboratorium Geofisika Jurusan Fisika untuk penyediaan fasilitas peralatan penelitian.

\section{DAFTAR PUSTAKA}

[1] D. J. Puradimaja, "Hidrogeologi Umum dan Sifat Fisik dan Kimia Air", Course Note for ITB Student, ITB, Bandung, 2005.

[2] D. Z. Herman, "Geothermal Potential And Conservation Thought", Center For Geological Resources, Bandung, 2006. 
[3] H. Andayany, and M. Y. S. Risakota, "Application Of Geotermometry Equation $\left(\mathrm{SiO}_{2}\right) \mathrm{p}$ In The Geothermal Area Both Haruku And Tehoru, Central Of Maluku", IJHMCR, Vol.2, Issue.04, pp 605-609, 2017.

[4] J. R. Kelibulin, "Thermal Analysis In Geothermal Area Of Oma-Haruku Based On A 2D Model", JAMFAS, Vol.1, p 23, 2016.

[5] Jr. C. Karr, "Infraredad Raman Spectroscopy of Lunar and Terrestrial Minerals", Academic press, New York, 13, 1975.

[6] K. Wohletz and G. Heiken, "Volcanology and Geothermal Energy, The Regents of The University of California", Printed in The United States of America, 1992.

[7] L. Marini, and A. E. Susangkyono, "Fluid Geochemistry of Ambon Island (Indonesia)", Geothermics, Vol. 28: 184-204, 1999.

[8] Pusat Sumber Daya Geologi, "Survei Pendahuluan Panas Bumi, Kabupaten Seram Bagian Barat dan Maluku Tengah, Provinsi Maluku", 2009.

[9] N. Saptadji, "Energi Panas Bumi di Indonesia", ITB Bandung, 2009.

[10] S. Tjokrosapoetro, E. Rusmana dan Suharsono, "Laporan Geologi Lembar Maluku Tengah", PPPG, Bandung. 32 $h+$ peta geologi skala 1:250.000., 2003

[11] W. A. Wardhana dkk., "Prospek energi panas bumi di Indonesia”, Elektro Indonesia, Edisi 15 November 1998. 